\title{
Os Horizontes de Prometeu. Considerações para uma Crítica da Modernidade ${ }^{1}$
}

CARLOS ALBERTO PLASTINO

\section{RESUMO}

$\mathrm{O}$ artigo discute inicialmente as concepções centrais do neoliberalismo e da multifacética crise de civilização, decorrentes da unilateralidade da perspectiva iluminista. Afirmando a necessidade de recuperar a perspectiva crítica, insere a consideração das políticas econômicas neoliberais e de suas conseqüências políticas, sociais e culturais na perspectiva da crise da modernidade. Considera a seguir as características centrais da cosmologia moderna, salientando o papel central do racionalismo, nas suas vertentes ontológica e gnosiológica. Apoiando-se nas contribuições da ciência contemporânea (em especial da física quântica) e da psicanálise, assinala o caminho seguido pela crítica daquelas concepções, orientadas no sentido de relativizar o determinismo, abrindo espaço para a consideração da criação e da emergência do radicalmente novo na história

Palavras chave: Neoliberalismo; crise de civilização; crise da modernidade. 


\section{Um Cenário Inquietante}

Está mais do que na hora de recuperar uma característica central do Iluminismo: a crítica - mesmo se, como se verá, seu exercício devesse hoje denunciar a unilateralidade do Iluminismo e da civilização forjada pela modernidade. O exercício da crítica torna-se hoje particularmente necessário, na medida em que a hegemonia do discurso neoliberal desqualifica qualquer discurso alternativo, impondo de fato o "discurso único", revestido com os emblemas de uma pretensa cientificidade. O discurso único é ufanista. Acena com um futuro de prosperidade, ressuscitando a crença na "mão invisível", a que atribui a capacidade de fazer surgir do feroz enfrentamento dos agentes econômicos no mercado a melhor solução possível.

Utilizando esse discurso anacrônico como expressão de cientificidade e realismo, o "discurso único" escamoteia cuidadosamente a questão do tipo de racionalidade que sustenta seu projeto de interpretação e construção da realidade social. Esvaziando qualquer perspectiva crítica, ele apresenta indicadores isolados como demonstração da pertinência de sua posição. Assim, o aumento da produtividade, o prodigioso progresso tecnológico, a globalização econômica e a estabilização - eterno primeiro passo para o crescimento com justiça social - são apresentados como prova do acerto das políticas econômicas neoliberais. Todavia, analisados de uma perspectiva que inclua o conjunto dos dados relevantes e não escamoteie a lógica do processo, esses indicadores não justificam nenhum tipo de ufanismo. Entre os dados relevantes, é preciso destacar o aumento do desemprego, que é indiscutivelmente de caráter estrutural e resulta, de um lado, do fantástico progresso tecnológico - super-acelerado sob o chicote da concorrência em mercados globalizados - e, de outro, da ausência de políticas públicas compensatórias. Considerado isoladamente, o crescimento da produtividade é, sem dúvida, um fenômeno positivo. Entretanto, sob uma ótica humanista - isto é, que priorize o interesse humano - esse crescimento constitui apenas um instrumento que, no contexto predatório da sociedade de mercado, está se revelando um desastre para os interesses globais da Humanidade.

Não se trata obviamente de satanizar o crescimento das forças produtivas, ressuscitando algum tipo de ludismo tardio, mas de questionar o contexto global no qual esse crescimento está sendo operado, denunciando suas consequiências deletérias. Trata-se, enfim, de colocar essas forças produtivas a serviço da Humanidade, submetendo a racionalidade parcial dos 
mercados à racionalidade global de um projeto social humanista. Não é do interesse da Humanidade um sistema que aumenta as desigualdades entre indivíduos, países e regiões, que incentiva mais a produção de bens supérfluos do que de primeira necessidade, que acelera a concentração de riqueza e a oligopolização da economia, que exacerba a violência multifacética, degrada a ética social e faz dos seres humanos inimigos na luta impiedosa pela sobrevivência em sociedades nas quais a solidariedade fica reduzida a iniciativas caridosas. $\mathrm{O}$ aumento do desemprego, da marginalidade, da desassistência, da violência, do desespero, da solidão, do consumo maciço de drogas - legais e ilegais - e do alcoolismo não é o resultado provisório de um processo de ajuste e muito menos um fenômeno isolado, desvinculado das políticas praticadas pelo neoliberalismo hegemônico. Essa degradação é conseqüência direta dessas políticas e integra o coração da racionalidade do modelo neoliberal, ao qual acompanha por toda parte como uma sombra.

Se isto é o resultado de uma análise global da situação, a projeção da situação atual conforme a lógica do sistema é ainda mais estarrecedora. Com efeito, a inevitável continuidade desse processo de crescimento da produtividade e de correlativo aumento do desemprego estrutural, num contexto de ausência de políticas compensatórias e de desarme ideológico dos setores populares e das forças progressistas, acena para cenários de exacerbação da situação atual. Repare-se que a problemática que nos ocupa excede largamente a questão da conveniência do Estado possuir ou não empresas produtivas. A questão central reside no papel que convém ou não outorgar ao poder público na regulação da vida econômica e social.

Essa regulação é necessária ou, como pretende o pensamento hegemônico, essa função reguladora deve ser deixada aos automatismos do mercado? Ora, como é sabido, a racionalidade do mercado é uma racionalidade parcial. Isto significa que ela é determinada pelo que é conveniente aos interesses do agente implicado em determinada decisão, não existindo nenhuma razão que permita deduzir que da soma dessas racionalidades individuais surgirá a racionalidade global. Assim, é do interesse de cada capital substituir trabalhadores por máquinas, visando a diminuir custos e aumentar a produtividade. Essa conduta, estritamente racional do ponto de vista dos interesses de cada fração do capital, redunda numa diminuição global do emprego e, conseqüentemente, numa diminuição da demanda efetiva. $\mathrm{Na}$ ausência de políticas compensatórias promovidas pela instância pública, a projeção dessa situação é a de um parque produtivo progressivamente automatizado e, de outro lado, de massas de 
desempregados. E, de novo, na ausência de um poder regulador capaz de estabelecer formas de distribuição da riqueza produzida não mediadas pelo mercado, a perspectiva é a convivência de quantidades fantásticas de mercadorias e de massas humanas desprovidas dos recursos necessários para consumi-las.

A racionalidade do mercado é uma racionalidade parcial, e quanto maior o grau de oligopolização, mais essa racionalidade é determinada pelos interesses de uma minoria. É uma lógica instrumental, totalmente desvinculada de uma lógica global estruturada em tomo dos interesses da Humanidade e de seus objetivos de solidariedade, liberdade e igualdade. Assim, como se viu, segundo essa lógica, o acréscimo da produtividade não resulta na diminuição do tempo de trabalho dos homens, nem no acesso destes a maior número de bens. Com respeito ao trabalho, muitos ficam sem ele, e os que conseguem conservá-lo devem trabalhar mais do que antes para ganhar a mesma coisa ou, freqüentemente, menos. Ainda segundo esta lógica, porque a Humanidade está muito mais rica e possui muito mais capacidade de produzir bens e serviços, é necessário diminuir ou cortar as conquistas sociais obtidas em mais de um século de lutas.

A racionalidade global não pode surgir do choque das racionalidades parciais. Ela só pode resultar de um projeto coletivo e democrático, implementado pela instância pública, aqui incluído o Estado. O Estado fortalecido e dotado dos recursos necessários ao cumprimento de seu papel de regular a vida econômica e social, e de procurar a racionalidade global, não é necessariamente um Estado proprietário. Como se afirmou acima, a questão do Estado e de seu papel excede largamente a questão das empresas públicas e de sua privatização. A conveniência de privatizar ou não as empresas estatais depende de uma série de considerações e só pode ser estabelecida em cada caso concreto. A questão de fundo continua sendo que o poder público precisa se dotar de todos os recursos político-institucionais e econômicos para exercer seu papel regulador. É a esta questão fundamental que devem se subordinar as decisões concernentes às privatizações.

Da perspectiva desse presente inquietante e desse futuro ameaçador, a proclamada racionalidade das políticas neoliberais constitui uma ironia macabra. Qual é o fundamento dessa racionalidade? Como se verá, longe de se sustentar em qualquer "dado natural" irredutível, ela foi historicamente construída a partir de uma concepção de sociedade como resultante da soma 
de indivíduos e destes como agentes motivados fundamentalmente pelo interesse material. Trata-se de uma concepção unilateral que empobrece a percepção de uma realidade muito mais complexa. A sociedade humana não é necessariamente - e não está condenada a ser - o cruzamento de milhões de cálculos individuais de custo-benefício, nem a arena de lutas competitivas de indivíduos maximizantes. Essa modalidade de sociedade humana e de indivíduo é um produto da história e não a manifestação de qualquer ordem natural. É preciso abandonar, na abordagem dessa questão fundamental sobre o natural no homem, as "generalidades antropológicas" sobre as quais se sustenta o discurso neoliberal. É preciso nesse terreno ouvir o que têm a dizer os saberes que exploram o conhecimento da "alma" humana e de seus produtos (psicologia profunda, antropologia).

O indivíduo isolado é uma ficção. Como já sabia Aristóteles, somos "animais políticos", o que significa não apenas que vivemos em sociedade, mas que somos constituídos em e a partir dessa sociedade. Para além das fantasias à Robinson Crusoé dos pensadores fundadores da modernidade, o saber produzido pela psicanálise nos aproxima dos complexos processos afetivos, intelectuais e corporais que nos constituem como seres desejantes no bojo da vida social.

Constituído a partir da cultura, o sujeito humano se relaciona conflitivamente com essa cultura que lhe impõe - através da lei - a limitação de sua onipotência como condição para a vida social e para a vida de cada sujeito (FREUD, 1986a; 1986b). Essa concepção do homem como ser constitutivamente social, tão afastado da imagem do individuo-átomo inventada pelo pensamento moderno, coloca a questão central da ética como requisito para a convivência civilizada. Voltarei a esta questão posteriormente.

Para além da antropologia especulativa, que define o homem como "essencialmente" bom, ou mau, ou maximizante etc., o saber psicanalítico nos mostra uma realidade humana extremamente complexa. Mostra-nos um sujeito dividido, pulsionalmente impelido à disrupção, à divisão e à morte, porém também pulsionalmente impelido para a unidade e a vida (FREUD, 1976). Ensina-nos também que os seres humanos não vivem em sociedade como conseqüência de um cálculo racional sobre a conveniência da associação. Como intuiu corretamente Rousseau (1963a; 1963b), é aos afetos humanos que se deve atribuir o caráter constitutivo da vida social e de suas modalidades. Aos afetos humanos como patrimônio antropológico (os humanos somos capazes de odiar 
e de amar, de destruir e criar, de gerar a vida ou de produzir a morte) efetivamente desenvolvido no seio das práticas sociais concretas das sociedades históricas. Certamente, o saber psicanalítico desautoriza qualquer ilusão em tomo da possibilidade de se atingir uma sociedade perfeita, isenta de conflitos (FREUD, 1986a). Desautoriza assim tanto a crença liberal em um equilíbrio automático promovido pelo mercado (SMITH, 1978), quanto à utopia marxista sustentada na concepção de indivíduos desalienados unificados pelo acesso à racionalidade plena (MARX e ENGELS, 1977). Nenhuma dessas duas crenças da modernidade é sustentável na perspectiva do saber psicanalítico. Desta mesma perspectiva, entretanto, se o conflito entre os homens aparece como inerradicável, a expansão da sociedade democrática, o progresso ético e a produção histórica de outras formas de subjetividade é possível. Afinal de contas, a espécie humana já foi canibal e deixou de sê-lo, ao menos no sentido estrito do termo...

O ufanismo do discurso neoliberal hegemônico - com vocação de discurso único - não pode esconder nem as conseqüências sociais e culturais do modelo, nem a articulação dessas consequiências com o tipo de racionalidade que orienta esse modelo. As conseqüências sociais de cunho negativo (expansão do desemprego, da violência, da marginalização e da miséria) já foram mencionadas: usando a linguagem coloquial, poder-se-ia dizer que estão "na cara" de nossas sociedades, tanto das centrais quanto das periféricas. O tipo de subjetividade que o modelo produz merece, entretanto, uma menção: a instauração, seja do mercado e das mercadorias como centro da vida social, seja da produtividade e do lucro como critérios centrais de relacionamento, determina a esmagadora hegemonia de práticas sociais inspiradas pelo individualismo e o materialismo. Essas práticas favorecem a emergência de um tipo de subjetividade narcísica e, ao mesmo tempo, amedrontada pela ferocidade do darwinismo social que rege a vida social sob o neoliberalismo. A solidão, o desespero, o uso maciço de drogas e o alcoolismo, enfim, a procura desesperada de sentido nos fundamentalismos e nas seitas religiosas, são outros tantos fenômenos que, exacerbados nas sociedades atuais, resultam diretamente do tipo de relações sociais, dos valores e crenças promovidos pelo discurso e pelas práticas sociais predadoras do neoliberalismo.

Entre as conseqüências negativas das políticas neoliberais, cuidadosamente escamoteadas pelo discurso único, é preciso salientar o esvaziamento e a limitação da democracia. Na verdade, essa limitação é uma condição para o estabelecimento pleno e para a conservação da "ordem neoliberal", como entenderam os teóricos conservadores da Comissão Trilateral, há quase 
três décadas. Essa limitação da democracia é paradoxal, posto que ela acontece num período de superação de regimes ditatoriais e de correlativa expansão dos regimes representativos. Todavia, ela é evidente. Em primeiro lugar, pela hegemonia sem precedentes atingida pelo discurso único e sua insistência em apresentar as políticas neoliberais como as únicas possíveis, científicas ou, ainda, realistas ou naturais. Em seguida, pela ausência efetiva de alternativas, resultante da desorientação das forças políticas progressistas e da deserção da socialdemocracia. E, ainda, pelo estreitamento do espaço público e pela fantástica capacidade de manipulação da sociedade, tomada possível pelo desenvolvimento dos meios de comunicação de massa e pelo controle oligopólico dos mesmos detido pelos setores dominantes.

O pensamento crítico não pode, como foi dito, limitar-se a desvelar a falácia do discurso hegemônico. A hegemonia do neoliberalismo e da selvageria darwinista que lhe é constitutiva, produz-se no bojo do fracasso das tentativas realizadas, no seio da modernidade, para construir sociedades solidárias e livres. Não é este o lugar para discutir as causas desses fracassos, excessivamente complexas para serem abordadas neste contexto. Todavia, a inviabilização desses projetos assinala que as raízes da crise são mais profundas, e que é preciso ultrapassar a crítica do capitalismo e submeter a exame a matriz geradora tanto do capitalismo como do denominado socialismo real. Essa matriz é a modernidade. Esta crítica é necessária e urgente. Não se trata obviamente de desconhecer os múltiplos aspectos positivos que fazem parte da modernidade, mas de denunciar a unilateralidade desta e suas consequiências. Isto é importante porque no paroxismo das contradições determinadas pela unilateralidade da perspectiva moderna como a convivência escandalosa de uma fantástica capacidade de produzir à custa da miséria de massas, a limitação da democracia, a produção histórica de subjetividades narcísicas, enfim, o profundo e crescente mal-estar vigente nas sociedades - anuncia-se uma crise de civilização que, de não ser superada, ameaça com levar a Humanidade para novas formas de barbárie.

\section{Razão e Complexidade}

A construção do imaginário moderno constitui fator essencial na invenção e produção da modernidade. Ele próprio foi construído no bojo da lenta dissolução do paradigma antigo, marcado por uma visão unitária, hierarquizada e teocêntrica, impregnado pela presença do sagrado (teofania) e, conseqüentemente, estruturado em tomo da concepção de uma ordem imutável. 
O conceito central da cosmologia moderna - isto é, da compreensão que a modernidade produz sobre o mundo e o homem - é o de racionalidade. Essa racionalidade possui uma dupla face, a da ontologia e a da gnosiologia. Pela primeira, o real é concebido à semelhança da máquina, cujo dinamismo é determinado por leis rigorosas, passíveis de serem conhecidas. É o reino do determinismo e da causalidade suficiente, potencialmente exprimível na linguagem exata das matemáticas. A segunda face do racionalismo da modernidade se situa no homem e na sua capacidade de conhecer. O homem é definido como um ser racional, capaz de aceder ao conhecimento do real e de sua organização e leis de movimento. É esta confiança na capacidade da razão para conhecer as leis que regem o real - e, em consequiência, na capacidade do homem para dominá-lo - que inspira o projeto prometéico da modernidade, sustentando a idéia-força de progresso (OLIVEIRA, 1966; SZAMOSI, 1988).

A concepção de um sujeito de conhecimento definido pela sua racionalidade e de um objeto organizado conforme determinações rigorosas e conhecíveis requer uma operação pela qual a razão se comporta como observadora externa de um mundo inteiramente regido pelo determinismo. A distinção cartesiana entre res-extensa e res-cogitans realiza essa operação, que inclui o próprio ser do homem. Seu corpo, separado de sua razão, passa a ser considerado como res-extensa. Como conseqüência dessa operação, são estabelecidos critérios de legitimação e deslegitimação das diversas formas de conhecimento. Da perspectiva da modernidade, o único conhecimento admissível é aquele adquirido pela razão conceitual. As outras formas de produção de conhecimento e de saber, forjadas pela Humanidade através de uma experiência milenar, que não falam linguagens quantitativas nem se organizam conforme a lógica racional, foram excluídas do campo dos conhecimentos aceitáveis. O reducionismo da concepção antropológica da modernidade - pelo qual o homem é definido por apenas uma de suas faculdades - provoca, assim, a mutilação das experiências de conhecimento da Humanidade (WHITMONT, 1969).

Desta perspectiva da cosmovisão moderna, de sua concepção da matéria, do determinismo que rege seu movimento, do processo de conhecimento, deriva a interpretação do mundo e do homem da modernidade e, consequientemente, seu sentido e sua ética. Pensando o real do mundo conforme a imagem de uma máquina, postulando o determinismo absoluto das leis que regem o funcionamento dessa máquina, a modernidade exclui, em última instância, a possibilidade de emergência do radicalmente novo, do que não é determinado, mas é criação. Assim sendo, essa perspectiva nega também a 
história (no sentido forte do termo, isto é, como criação e emergência do novo) (CASTORIADIS, 1986). Como tentei mostrar em outros trabalhos, mesmo o marxismo, provavelmente o pensamento mais historicista no interior da modernidade, postula uma sorte de determinismo, depositado no comportamento necessariamente racional do homem desalienado. Para dizê-lo com a lúcida frase de Engels, o conceito de liberdade se restringe a ser a consciência da necessidade.

A concepção de um real determinado por suas leis constitutivas e a possibilidade de se aceder ao conhecimento dessas leis inspira à modernidade seu projeto de domínio. Na expressão de Bacon, a natureza devia ser reduzida à obediência, cabendo à ciência a tarefa de arrancar-lhe seus segredos (DURANT, 1996). Este projeto prometéico, contudo, não se limitava à natureza externa, mas incluía o próprio homem. Por analogia com a física, a concepção antropológica pensa o homem como constituindo o mínimo elemento irredutível da vida social. Dotado de racionalidade, esse in-divíduo é suposto ter decidido - em algum momento mítico - viver em sociedade.

Para além das significativas diferenças existentes entre os fundadores da reflexão política da modernidade (ROUSSEAU, 1963a e b; HOBBES, 1974; LOCKE, 1986), todos eles sustentam a existência de um direito natural acessível à razão humana. Esse direito exprime o que o homem é conforme sua natureza, devendo-se, a partir da consideração dessa natureza, estabelecer a forma de associação mais racional, isto é, mais adequada à natureza do homem. Essas formas de associação e de organização da vida social não deveriam ser motivo de opiniões - e de conflitos - mas conseqüências necessárias e irrefutáveis de um saber sobre o homem e a sociedade, que poderia reivindicar o mesmo nível de certeza que as ciências matemáticas. Assim, nas palavras de Spinoza, o objetivo da ciência política seria demonstrar, com argumentos certos e irrefutáveis, isto é, deduzir da condição mesma da natureza humana, aqueles princípios que melhor se adequassem à prática, devendo-se proceder a essa pesquisa científica com a mesma liberdade de ânimo que se aplica às matemáticas. $\mathrm{Na}$ pena de Locke, seria "a partir de proposições evidentes por si mesmas, mediante consequiências necessárias, tão incontestáveis como as das matemáticas, que se poderia obter a medida do justo e do injusto, se alguém quisesse se aplicar a esta ciência com a mesma indiferença e atenção que põe na outra”. Há, pois, a crença numa natureza humana modificável, cujas características principais, acessíveis à razão, permitem a formulação das normas que, por serem naturais, devem reger a convivência entre os homens. Essa crença faz parte da 
cosmovisão da modernidade e se harmoniza com sua lógica. Ela preside as concepções antropológicas fundacionais da modernidade e, na sua versão liberal, do discurso hoje hegemônico. Também não falta, nessa reedição, a afirmação da "cientificidade" dessa específica concepção do homem, nem do caráter "necessário" das formas de organização social "deduzidas" da "natureza humana".

A inversão de perspectivas, operada na nossa contemporaneidade a respeito da cosmovisão moderna, pode ser apreciada na consideração do que, em cada um desses dois momentos, provoca deslumbramento. A modernidade se deslumbrou com a razão, com a sua capacidade de desvelar o ser do mundo, ele próprio pensado a partir da racionalidade de suas leis constitutivas, como uma máquina. A ambição e o objetivo de atingir e formular matematicamente o ser do real indica a concepção de um mundo, em última instância, simples. Já o que deslumbra nossa contemporaneidade é a complexidade do real; complexidade tomada mais profunda e evidente à medida que se desdobram nossas experiências e nosso conhecimento. Podemos considerar essa complexidade com relação ao sujeito, ao objeto e à relação sujeito-objeto.

Complexidade do sujeito: da perspectiva do saber sobre o homem produzido pela psicanálise, bem como da perspectiva de outras tradições, a definição do homem como sujeito unificado pela sua razão se torna insustentável. A descoberta do inconsciente e de seus poderes projeta uma concepção extraordinariamente mais rica e plural do homem e da experiência humana.

Como se sugeriu acima, o pensamento moderno pensou o homem como constituindo inicialmente um indivíduo isolado, posteriormente associado como consequiência de uma decisão racional. Como é sabido, essa maneira de pensar o homem e sua relação com a sociedade foi inspirada por analogia com a Física, cuja concepção do ser natural postulava a existência, no nível mais básico e indivisível, de partículas materiais distintas entre si que colidem repelindo-se e se atraindo.

Também na abordagem da questão das relações dos homens com a sociedade, o saber produzido pela psicanálise fornece uma perspectiva muito mais rica e complexa. Desta perspectiva, o homem aparece como constituído, desde a cultura, numa experiência de pertinência comandada sobretudo pelos afetos. Complexidade também do sujeito como sujeito de conhecimento, não limitado à potência de sua razão, mas concebido como capaz de experiências de conhecimento com seu inconsciente e até com seu corpo. Recupera-se, 
assim, a significação dos mitos. Longe de constituir a superstição de épocas distantes e atrasadas, os mitos veiculam conhecimentos produzidos pela Humanidade por uma via alheia à razão conceitual. Eles exprimem a compreensão ancestral de nossas paixões.

Projeção do inconsciente, no dizer de Freud (1975), os mitos não oferecem um conhecimento comparável ao científico, posto que se inscrevem em outros registros e são produzidos por outros caminhos. Todavia, não é um conhecimento inferior. Ele não está superado, como pensa às vezes a ingênua arrogância iluminista, mas recalcado pela ciência.

Junto com Freud, de quem tomei esta última sentença, resta surpreenderse com o saber dos poetas. Complexidade do sujeito, enfim, inteiramente diversa da simplificada perspectiva da modernidade. Nesta, a unidade do sujeito se obtém à custa da sua mutilação. Da perspectiva que estamos comentando, a cisão do sujeito vai acompanhada pela sua riqueza e complexidade.

A modernidade construiu seu paradigma de conhecimento sob o impacto provocado pelos extraordinários desenvolvimentos da física newtoniana. Como assinalamos acima, não foi apenas a natureza e seu dinamismo que ganharam com a Física clássica um novo modelo de inteligibilidade. Esse novo modelo se estendeu ao terreno do conhecimento da sociedade e do indivíduo, fornecendo a base das teorias políticas e sociais modernas. Esse modelo, rigorosamente determinista, se sustenta na afirmação de um nível básico do ser, nível a partir do qual este se torna indivisível. Como lembrei acima, segundo este modelo, na sua manifestação mais elementar, a realidade consiste em partículas indivisíveis, que colidem entre si, se atraindo e repelindo. Sólidas e separadas, essas partículas básicas e indivisíveis ocupam um lugar próprio e definido no tempo e no espaço. Assim, segundo este modelo de inteligibilidade, a matéria é constituída de partículas e as ondas não são consideradas coisas em si mesmas, mas apenas vibrações que têm lugar num campo subjacente, denominado éter. No interior deste modelo, o movimento é pensado como deslocamento de um objeto no espaço em consequiência de uma causa. Assim, qualquer efeito experimentado por um dos componentes básicos e indivisíveis da realidade, ou por qualquer combinação deles, deve resultar de uma causa que o explique (SANTOS, 1989; s/d).

Esse modelo não apenas coincidiu com o senso comum, mas demonstrou ser extraordinariamente fecundo na manipulação do mundo natural. Foi precisamente a partir dessa capacidade de manipulação e do fascínio que esta exercia, que ele passou a ser considerado como o reflexo do ser do real. Entretanto, 
a posterior evolução do conhecimento desse mesmo mundo natural desautorizou a última afirmação. Com efeito, a representação de um real composto em seu nível mais básico por partículas indivisíveis ruiu sob o impacto das descobertas da física contemporânea. Segundo a Física quântica, no nível subatômico, o real pode ser descrito alternativamente como ondas ou como partículas, sendo que nenhuma das duas descrições, isoladamente, possui real precisão. A consideração simultânea dos dois aspectos do real - partícula e onda -é necessária para tentar uma descrição pertinente da natureza das coisas, mas essa consideração simultânea é, rigorosamente, impossível. Assim, a dualidade onda e partícula constitui o aspecto mais básico da realidade e a descrição do ser elementar exige as duas descrições simultaneamente. É o princípio da complementaridade.

Entretanto, embora apenas partícula e onda juntas constituam a matéria e nenhum dos estados isolados - onda e partícula - possa nos dar um quadro completo dela, só é possível focalizar um estado de cada vez. As descrições do ser como onda e como partícula se excluem mutuamente num tempo dado, de maneira que o conhecimento da exata posição de uma partícula exclui a possibilidade de medir sua velocidade de deslocamento. A impossibilidade de medir ambos os aspectos ao mesmo tempo fundamenta o princípio da incerteza. Assim, se da perspectiva newtoniana tudo na realidade física é potencialmente fixo, determinado e mensurável, da perspectiva quântica nada é fixo, nem totalmente mensurável, mas tudo é permanentemente indeterminado. A realidade fundamental é, em si mesma, essencialmente indeterminada. Tudo nela é uma questão de probabilidade. O onipresente determinismo da Física clássica é substituído, na Física quântica, pela probabilidade.

Para nosso senso comum, educado pela cosmovisão moderna sustentada pela Física newtoniana, essa perspectiva é insólita. Tão insólita, provavelmente, quanto significou a perspectiva moderna para a mentalidade medieval. Como é óbvio, neste nível, a questão em jogo ultrapassa o terreno da física para, a partir desta, incursionar nas questões filosóficas fundamentais. A questão do relacionamento entre o todo e a parte está, obviamente, entre essas questões. Esta é, sem dúvida, uma questão maior, cuja abordagem, mesmo sumária, é impossível nestas páginas. Entretanto, no intuito de tomar evidente o caráter histórico do modelo de inteligibilidade da modernidade, tentarei indicar as linhas centrais de abordagem da questão.

Como se viu, a modernidade pensou a organização do real a partir de um nível básico do ser, partículas in-divisas cujas formas de relacionamento 
constituem a totalidade. Assim, o todo é pensado a partir das partes e o relacionamento entre as partes conforme o princípio da causalidade, isto é, qualquer efeito experimentado por uma parte, deve ter, necessariamente, uma causa que a explique em outra parte. O modelo de inteligibilidade do ser produzido pela Física contemporânea é diferente. Não apenas porque o movimento das partículas elementares - o "pulo" de elétron de uma órbita atômica a outra - é espontâneo e não provocado, mas porque a compreensão do movimento que deriva desses processos permite pensar a partir de outra perspectiva o relacionamento entre a parte e o todo. Coisas e acontecimentos que a Física clássica pensa como entidades separadas pelo espaço e pelo tempo são concebidos pela Física quântica como integralmente ligadas, como aspectos múltiplos de um todo maior, através do qual as existências individuais ganham definição e sentido. Desta nova perspectiva, uma parte pode influenciar outra à distância, isto é, sem que exista troca aparente de força ou energia. Haveria assim um comportamento "sintonizado" entre as partes, sem que seja possível estabelecer uma relação de causa e efeito. Esse tipo de relacionamento - sincrônico - supõe uma concepção unitária do ser, permitindo estabelecer sugestivas comparações entre o modelo de inteligibilidade produzido pela Física quântica e as concepções do ser elaboradas por outras tradições, das orientais à pré-socrática.

As considerações vistas acima têm por único intuito ilustrar a enorme complexidade da problemática do objeto, a partir dos trabalhos mais avançados da ciência contemporânea. A sensação de perplexidade que tal perspectiva desperta aumenta ainda mais quando se considera a maneira como ela enfoca o relacionamento entre o sujeito de conhecimento e seu objeto. Nesse relacionamento, a participação do observador é crucial para a transformação das múltiplas probabilidades contidas na realidade quântica, na realidade fixa que constitui o mundo. Trata-se, pois, de um universo participativo, pelo qual, para utilizar uma expressão de Prigogine (1990), a realidade só nos é revelada através de uma construção ativa da qual participamos. Da perspectiva da concepção rigorosamente determinística da Física newtoniana, constitui um problema explicar como algo de novo poderia acontecer. Da perspectiva da Física quântica, na qual no nível mais fundamental a realidade é apenas uma indefinida situação de infinitas probabilidades, o problema é explicar como algo pode passar a existir. A resposta a esta questão, como vimos, atribui ao sujeito papel fundamental na produção da realidade. Seria difícil pensar uma concepção mais engajada do processo de conhecimento e também afirmar de maneira mais fundamental a radical historicidade da natureza. 
A incidência de uma cosmovisão na produção de práticas concretas de produção da subjetividade passa obviamente por processos longos e extremamente complexos. Para compreender isto, basta pensar nas profundas transformações que - durante vários séculos - operaram a substituição da cosmovisão medieval pela moderna. Trata-se de verdadeiras mutações culturais que, por sua complexidade, são extremamente difíceis de se reconstruir teoricamente sem incorrer em grosseiras simplificações. Se isto é assim quando se trata de processos históricos concluídos, as dificuldades são muito maiores quando se trata de processos em curso. Por sua própria característica, a emergência histórica do novo, do não-determinado, é rigorosamente imprevisível. Porém, se o conteúdo do processo é imprevisível, sua orientação ou sentido pode ser influenciado no aqui e agora de cada momento histórico. Desta perspectiva, se o processo em curso se caracteriza pela radicalização das concepções individualistas fundacionais da modernidade, sua superação indica o caminho do desenvolvimento da solidariedade. Para além de apontar um determinado tipo de conduta, esse termo alude a um dado central da experiência humana: a que define o homem não apenas como sendo constitutivamente um ser social, mas ainda um ser profundamente relacionado com a natureza, ao ponto de, ao destruí-la, ameaçar seu próprio futuro.

A superação da cosmologia da modernidade não pode significar o retomo à cosmologia antiga, marcada pela idéia da hierarquia. A modernidade produziu, apesar da unilateralidade de sua perspectiva, práticas e concepções indiscutivelmente positivas. $\mathrm{O}$ reconhecimento dos direitos individuais em face de qualquer forma de opressão, com todos seus desdobramentos, constitui um patrimônio da Humanidade, mesmo se na sua aplicação prática eles alcancem apenas uma minoria e estejam cada vez mais ameaçados. A cosmovisão que os novos saberes começam a delinear evoca uma unidade sem hierarquias, na qual os seres, longe de estarem justapostos, se apresentam profundamente relacionados e articulados. Uma cosmovisão, em suma, marcada pela solidariedade. Algumas breves considerações sobre o mito de Prometeu, cujo nome serve de título a estas reflexões, pode ajudar a compreender a significação do que foi dito.

Tradicionalmente, o mito de Prometeu foi interpretado como a narrativa da libertação da espécie humana, a conquista da autonomia em face do poder, tomada possível pela apropriação - roubo - do fogo, símbolo da razão. Por isso, Prometeu foi o símbolo do Iluminismo. Seu feito heróico de roubar de Zeus o fogo antecipa e representa a saga que, pela revolução científica, política e in- 
dustrial, se propunha levar o homem a superar sua minoridade, atingir sua autonomia e, pelo caminho do progresso, tomar-se senhor do mundo. Por isso a imagem de Prometeu foi carregada em triunfo durante a grande Revolução Francesa de 1789, seu barrete frígio enfeitando a cabeça dos revolucionários. Por isso também, anos depois, seu nome se tornou símbolo da Revolução Industrial, batizando máquinas e locomotivas. Assim, ele é o símbolo do progresso. Porém, sua imagem também aparecia no Palácio da Indústria Atômica Soviética, indústria da qual faz parte Chemobyl.

Esta última frase poderia sugerir a associação entre progresso e desastre e, por esta via, a condenação do progresso. Não se trata obviamente disto. Não é retornando a uma situação de heteronomia e minoridade que os homens superarão os perigos que nos ameaçam. Heteronomia e minoridade, por sinal, que se expandem rapidamente num mundo crescentemente despolitizado e dominado pelo poder econômico e pela mídia. A crítica da modernidade, em todo caso, não pretende propor o retomo à pré-modernidade, mas a superação da unilateralidade desta.

Essa unilateralidade, como tentei dizer acima, deriva da mutilação que o racionalismo produz na concepção do ser do homem. Definido como ser de razão, ele é privado das outras faculdades que o constituem. Imaginação, afeto e desejo, intuição - a percepção do inconsciente - todas essas características constitutivas do ser do homem foram consideradas fatores que perturbam a razão e, conseqüentemente, são desvalorizadas, ignoradas ou recalcadas. Como é sabido, essas características são comumente atribuídas pela nossa cultura ao feminino, de modo que não é surpreendente que sua desvalorização e recalque tenham coincidido com a opressão sofrida pelas mulheres.

Neste ponto, acho interessante retomar o comentário do mito de Prometeu. As versões de Hesíodo e Ésquilo parecem representar uma expressão tardia de um mito muito mais antigo. Uma reelaboração do mito no contexto do estabelecimento da sociedade patriarcal, reelaboração na qual o papel do feminino é apresentado de forma bastante negativa. Pandora sendo a portadora de todas as doenças e Tétis ameaçando a fecundidade de Zeus.

Entretanto, na versão mais antiga do mito, anterior, portanto, à sociedade patriarcal, a história é contada de outro modo. Prometeu é apresentado aí com um Kabire, um anão, semelhante aos que atualmente povoam os contos infantis e enfeitam nossos jardins. Este Prometeu remonta às antigas religiões matriarcais, representando o ajudante e acompanhante fálico da grande Deusa 
Mãe. Representavam a sabedoria e a fecundidade, a vida e o mistério. Desta forma, o castigo infligido a Prometeu - ser acorrentado e atacado pela águia que lhe rói o fígado - tem, desta perspectiva, outra significação. Símbolo da vida, permanentemente renascendo a cada noite, o fígado representa também a Lua e o feminino. Sempre recriado na noite, sempre destruído de dia pela águia, o cão de Zeus. A unilateral idade da razão significa, como vimos, a negação de todos esses aspectos constitutivos do homem, associados à feminilidade. Se isto é assim, as raízes da crise remontam a bem mais longe, constituindo o mundo moderno uma manifestação de um modelo mais antigo e abrangente de sociedade, a sociedade patriarcal.

Como afirmei acima, a crítica da modernidade não é assimilável ao enaltecimento da cosmovisão que a precedeu, hierarquizada, acorrentada a uma idéia de ordem natural e organizada num sistema gerador de e sustentado pela heteronomia e a minoridade dos homens. Não é, portanto, às conquistas da razão e da autonomia que se deve dirigir a crítica da modernidade, mas à ruptura produzida entre o homem, partes importantes de seu ser e seu ambiente vital. Considerar e respeitar a natureza, incluindo a do próprio homem, não significa necessariamente aderir a uma concepção determinista da existência, subordinando a criatividade humana a determinações biológicas ou outras. Mas significa abandonar a arrogante posição de conquistador de um mundo estranho, para assumir a radical pertinência a um real extraordinariamente rico e complexo, que contribuímos para criar quando o conhecemos. O mundo natural não é um inimigo a conquistar, como pensou o mundo moderno, mas, como nós, expressão da vida. E também condição para nossa vida. Convém lembrar que a palavra latina natura significa "a que vai nascer".

A emergência de uma nova ontologia, caracterizada pela historicidade de todas as coisas, constitui uma perspectiva central da cosmovisão emergente. Assim, a relação dos homens com a natureza, nesta perspectiva, é pensada não como adequação a uma ordem natural eterna e imodificável, mas como uma relação com sistemas abertos. Se o todo está em construção com a nossa participação, a responsabilidade ética cresce na exata dimensão de nossa liberdade.

Comentei acima que a solidariedade me parece ser uma característica central da cosmovisão emergente. Entretanto, ela resultará cada vez menos das necessidades de funcionamento do sistema e dependerá cada vez mais da vontade política dos homens, orientada pelas opções éticas. Entretanto, como pensar uma ética no interior de uma concepção que afirma a historicidade de 
todas as coisas? Não parece possível, neste contexto, sustentar princípios éticos fazendo-os derivar da sua adequação à ordem natural, já que essa mesma ordem está em permanente construção. Mais do que se fundamentar em uma "verdade", a ética parece dever responder, assim, a um movimento que não é da ordem do saber, mas que pertence ao campo do desejo. A ética possível de ser pensada no interior de um sistema aberto e participativo caracterizado pelo estreito relacionamento do todo e as partes parece ser a ética da vida. A opção pela vida em oposição à morte e à destruição, se não pode ser derivada de uma "verdade", pode, em compensação, resultar de uma opção em favor de um dos movimentos fundamentais que animam a alma humana. A construção de circunstâncias que permitam o fortalecimento dessa opção de vida, diminuindo o peso do movimento destrutivo que também se aninha no humano, constitui o terreno concreto no qual se colocam as opções éticas.

Gostaria de indicar, neste ponto, a importância da reflexão grega anterior ao aprisionamento do pensamento pela razão conceitual. Ética, na acepção produzida na Grécia antiga, significa morada, entendida como um lugar para se viver, um lugar na sociedade (BOHADANA, 1994). Um comportamento ético é, portanto, aquele que, respeitando o direito dos outros em aceder também a um lugar para viver, faz possível a vida civilizada. Torna-se evidente, então, tanto a estreita relação existente entre a ética e a democracia -entendida como o reconhecimento do outro e de seus direitos - quanto a característica centralmente antidemocrática da concepção neoliberal. É bom lembrar, neste ponto, que o modelo econômico neoliberal, hoje hegemônico, custa aos países pobres, a cada dois dias, a morte de uma população equivalente à assassinada pelas bombas atômicas jogadas sobre o Japão. Para essa população, o neoliberalismo hegemônico nega o direito a uma "morada" (PLASTINO, 1994).

Imaginar hoje a possibilidade de construir uma sociedade solidária pode parecer uma prova de incurável propensão para a utopia. E efetivamente é assim. Mas é também dar provas de prudência e razoabilidade. Com efeito, a continuar a atual orientação das relações vigentes entre os homens e destes com a natureza, o resultado que aguarda a Humanidade é a catástrofe. Todos os informes sérios dedicados a estudar os mais diversos aspectos da vida social, das questões ecológicas à problemática da pobreza, coincidem no pessimismo de seus diagnósticos. Assim, pensar e trabalhar a favor de uma mudança radical - de uma verdadeira mutação - constitui uma atitude prudente e razoável, visto que é a razão que nos indica não apenas os riscos que nos espreitam no caminho que estamos transitando, mas também os contornos de 
uma nova cosmovisão. Assumindo o risco de ser repetitivo, convém lembrar que a crítica do racionalismo não equivale a renunciar à razão. O racionalismo caracteriza uma mutilação do humano e, portanto, uma perspectiva unilateral da vida. A razão constitui uma faculdade fundamental, da qual precisamos mais do que nunca para superar as catástrofes com que nos ameaça o racionalismo.

Nosso tempo já foi identificado como sendo o do fim das utopias e da história. E, de fato, a ausência de expectativas de algo diferente do existente, que, como projeto ou esperança, fornecia um sentido à vida, constitui uma característica de nossa contemporaneidade. É provável que este seja o primeiro período da história em que os homens vivem sem utopias, já que, até o advento da modernidade e o correlato processo de dessacralização, a referência utópica geradora do sentido da vida se situava, obviamente, na esfera religiosa. Depois, já na modernidade, o projeto prometéico de domínio racional da natureza e da sociedade projetou utopias antagônicas, embora originárias da mesma matriz. Do progresso indefinido movido pela expansão da racionalidade científica e tecnológica à sociedade comunista, as utopias da modernidade produziram os diversos sentidos que moveram a história moderna. Essas utopias, embora tendo constituído a matriz de movimentos sociais antagônicos que se enfrentaram na história moderna, compartilham de uma matriz mais abrangente, cujo fulcro é o conceito de racionalidade.

Com efeito, por um lado, o homem é pensado nessa matriz unilateralmente como constituído exclusivamente por sua racionalidade, radicando nessa exclusividade o reducionismo racionalista, segundo o qual o conhecimento e a gestão do real são monopolizados pela razão. Por outro lado, o próprio real - o mundo e as coisas do mundo - é pensado como organizado segundo leis deterministas rigorosas conhecíveis pelo homem. É essa racionalidade, hegemônica na concepção antropológica e ontológica da modernidade que alimenta seu projeto prometéico.

Entretanto, esse projeto ameaça hoje naufragar nas catástrofes ecológicas que se anunciam e na barbárie de sociedades ao mesmo tempo economicamente ricas e socialmente miseráveis; nas virulentas contradições entre o fantástico potencial produtivo produzido pela razão instrumental e a marginalização, a miséria e a exclusão produzidas pelos interesses predadores daqueles que detêm o poder efetivo nessas sociedades. Evidentemente, o naufrágio da utopia da modernidade não é de hoje e as denominadas consequiências negativas do progresso são já velhas conhecidas da Humanidade. 
Persistia, entretanto, a expectativa de construir sociedades mais justas e solidárias, inspirando projetos alternativos e antagônicos que arquitetaram os processos e conflitos políticos deste século. Opostos ao capitalismo, esses projetos se sustentavam sobre a crença na possibilidade de transformar os homens e as sociedades, constituindo as utopias contemporâneas. $\mathrm{O}$ fracasso dos regimes ditos do socialismo real, bem como o abandono dos projetos societários social-democráticos, marcaram nos anos recentes o fim dessas utopias. Desqualificadas como expressão de imaturidade, foram substituídas por uma perspectiva dita "realista" que sustenta a imutabilidade da natureza humana, declarando ser impossível transformar o comportamento individualista, utilitarista, maximizante e egoísta. Os arautos do fim das utopias postulam uma "essência" humana muito próxima à de um macaco egoísta dotado de razão instrumental. Sustentam com esse pretenso "realismo" uma concepção rigorosamente determinista. Conservam do paradigma da modernidade tanto essa concepção determinista como um racionalismo cada vez mais reduzido aos seus aspectos instrumentais, abandonando de fato seu projeto libertário, igualitário e fraterno. Com um cinismo disfarçado de lucidez, afirmam ser esta a única atitude possível, ignorando arrogantemente as perspectivas que surgem das críticas radicais que tem sofrido o paradigma que as sustenta.

Quando os teóricos conservadores proclamam o fim das utopias, eles não pretendem apenas assinalar o esgotamento de um concreto projeto histórico. Eles pretendem anunciar o triunfo da racionalidade e a correlativa "superação de uma mentalidade atrasada e ideológica". Isto é diferente de afirmar que nossa época está órfã de utopias. O que, da perspectiva conservadora, ressoa como um sinal de progresso sob a ótica aqui apresentada, representa mais um sintoma do esvaziamento de um projeto que, se não for revisto desde suas raízes, ameaça a própria continuidade da vida civilizada. Da perspectiva conservadora, utopia é sinal de atraso porque aquela se sustenta sobre a concepção naturalista do homem, descrendo das possibilidades de transformação. $\mathrm{Na}$ perspectiva progressista, o real não se esgota no existente. Também o potencial faz parte do real. Por isso, utopia é um projeto de algo que ainda não existe, mas que é possível construir. Ela se sustenta numa concepção historicista segundo a qual os homens e as sociedades se constroem por suas práticas e seu imaginário.

Esta oposição me parece fundamental. É que as considerações vistas acima, a despeito de seu caráter sumário, assinalam a existência de um impasse civilizatório. Impasse que, como dizia no início deste trabalho, torna 
necessária e urgente a recuperação de uma atitude central na genealogia da modernidade: a crítica. Não se trata obviamente de condenar a modernidade, nem de ignorar seus múltiplos aspectos positivos, mas de denunciar a unilateralidade de suas concepções centrais sobre o homem, as relações sociais e as relações com a natureza. Torna-se necessário proceder a uma crítica radical - das raízes - de um modelo que, como todos os outros, é um modelo historicamente construído.

A afirmação da historicidade - e, portanto, a contingência - das formas de produção do homem e da vida social contesta a afirmação central da ideologia hegemônica: o caráter natural e, portanto, necessário e sem alternativas das formas vigentes de organização social. Por isso convém que a crítica da sociedade existente se sustente na crítica da concepção determinista - central para a perspectiva antropológica e ontológica da modernidade - demonstrando que, longe de espelhar qualquer "verdade" anistórica, constitui a expressão de um imaginário construído e conseqüentemente modificável. Ele constitui uma maneira entre outras possíveis de organizar e, portanto, de orientar a aventura humana.

É isto que faz da luta pela democracia a única via possível para superar a situação atual e seus catastróficos desenvolvimentos previsíveis. A profunda mudança operada nestes anos se coloca na pauta do esgotamento das perspectivas teleológicas, isto é, das filosofias da história que proviam um sentido transcendente aos processos históricos. A radical transformação da perspectiva científica liqüidou, como se viu, a metáfora do mundo-máquina, relativizou a perspectiva determinística, transformou o conceito de matéria e, tomando evidente uma fantástica complexidade do ser, redefiniu e relativizou a significação da causalidade. Existe certamente uma lógica dos processos sociais, mas eles não estão rigorosamente determinados. Assim como na natureza, na história também há lugar para o aparecimento do novo, do imprevisível. Todavia, esse novo só pode ser produto do agir humano. Por isso, para existir, o novo exige ser imaginado e depois produzido na prática concreta das relações sociais.

É neste ponto que o aprofundamento da democracia é fundamental. Os processos de globalização, expansão tecnológica e da produtividade são, ao que parece, irreversíveis. Todavia, não precisam necessariamente ser realizados sob a hegemonia e conforme os interesses conservadores dos ricos. Se assim está acontecendo - e isto é indiscutível - é porque a conjuntura histórica é de brutal enfraquecimento dos movimentos populares no contexto de crise 
ideológica e política da esquerda. Esse processo poderia ter outro signo, e é essencial que o tenha se queremos fugir do futuro inquietante que se projeta hoje. Para isto é preciso desenvolver a democracia, de maneira que não apenas o processo de transformação incorpore a lógica dos interesses dos povos e das maiorias, mas que a própria prática da democracia crie um movimento de desenvolvimento da cidadania, da politização e de recuperação e expansão do espaço público. A reversão do esvaziamento democrático, praticado com sucesso pelo neoliberalismo, parece fundamental para o futuro da Humanidade.

\section{Referências}

BOHADANA, E. Ética e psicanálise. Figura e discurso. Cadernos de Psicanálise, ano 11, n. 14, 1994.

CASTORIADIS, C. A instituição imaginária da sociedade. Rio de Janeiro: Paz e Terra, 1986.

DURANT, W. A história da filosofia. São Paulo: Abril, 1996 (Coleção Os Pensadores).

FREUD, S. Psicopatología de la vida cotidiana. Buenos Aires: Amorrortu, 1975. v. VI.

v. XVID.

. Más allá dei principio del placer. Buenos Aires: Amorrortu, 1976.

. EI malestar en la cultura. Buenos Aires: Amorrortu, 1986. v. XXI.

Inhibición, síntoma y angustia. Buenos Aires: Amorrortu, 1986b. v.XX.

HOBBES, T. Leviatã. São Paulo: Abril, 1974 (Coleção Os Pensadores).

LOCKE, J. Segundo Tratado sobre o Governo Civil. São Paulo: Editora Abril, 1986 (Coleção Os Pensadores).

MARX, K.; ENGELS, F. A ideologia alemã. São Paulo: Grijalbo, 1977.

OLIVEIRA, L. A. Por um novo materialismo. In:

Contemporaneidade e novas tecnologias. Rio de Janeiro: Sette Letras, 1966.

PLASTINO, C. A. Ética da psicanálise. Sociedade e engajamento. Cadernos de Psicanálise, ano 11, n. 14, 1994. 
PRIGOGINE, I.; STREVIGERS, I. La nueva alianza. Metamorfosis de Ia ciencia. Madri: Alianza Editorial,1990.

ROUSSEAU, J.-J. (1963a), Discours sur l'origine de l'inégalité parmi les hommes. Paris: Union Générale d'Éditions, 1963(a).

. Du contrat social. Paris: Union Générale d'Éditions,1963(b).

SANTOS, B. S. Um discurso sobre as ciências na transição para uma ciência pós-moderna. Porto Alegre: Estudos Avançados, s/d.

. Introdução a uma ciência pós-moderna. Rio de Janeiro: Graal,

1989.

SMITH, A. Investigação sobre a natureza e as causas da riqueza das nações. São Paulo: Abril Cultural, 1978 (Coleção Os Pensadores).

SZAMOSI, G. Tempo e espaço: as dimensões gêmeas. Rio de Janeiro: Zahar, 1988.

WHITMONT, E. A busca do símbolo. São Paulo: Cultrix, 1969.

\section{NOTAS}

${ }^{1}$ Publicado em Physis, v. 6, n. 1/2, p. 195-216, 1996.

${ }^{2}$ Psicanalista; Notório Saber em Ciências Políticas pela Pontifícia Universidade Católica do Rio de Janeiro; professor adjunto do Departamento de Políticas e Instituições de Saúde do Instituto de Medicina Social da UERJ. E-mail: cap@ centroin.com.br 
Os Horizontes de Prometeu...

\section{ABSTRACT}

Between Realism and Fiction: Representations of Race, Sexuality, and Prometeus' Scenarios: Toward a Critique of Modernity

This paper begins by putting forth the argument about the main concepts of neoliberalism and of the multifacetted crisis of civilization issuing from the unilateral illuministic perspective. Asserting the need to recover the critical viewpoint, it includes the analysis of neoliberal economic policies and their political, social and cultural outcome from the standpoint of the modernity crisis. It goes on to ponder the main features of modern cosmology, highlighting the fullrum role of rationalism in both its ontological and gnoseological approaches. Seeking support on the contributions of contemporary Science (particularly Quantum Physics) and of Psychoanalysis, it points out the route taken by the critique of those concepts, targetted towards the relativity of determinism and making room for the consideration of creation and of the emergence of the radically new in History.

Key words: Neo-liberalism; crisis of civilization; modernity crisis. 